\title{
Erratum to: Spontaneous regression of a parafalcine meningioma in a multiple sclerosis patient being treated with interferon beta-1a
}

Luke Galloway $^{1,2} \cdot$ Niki Vakili $^{2} \cdot$ Julian Spears $^{2}$

Published online: 10 December 2016

(C) Springer-Verlag Wien 2016

Erratum to: Acta Neurochir

DOI 10.1007/s00701-016-3019-6

The correct figure 1 legend should be the below:

The online version of the original article can be found at doi:10.1007 /s00701-016-3019-6.

Luke Galloway

lukegalloway14@hotmail.com

1 Cardiff and Vale University Health Board, Heath Park,

Cardiff, Wales, UK

2 Department of Neurosurgery, St. Michael's Hospital,

Toronto, Canada 
Fig. 1 2006: T1 + GAD coronal MRI (a), T1 + GAD axial MRI

(b) and axial flair MRI (c)

measuring $2.6 \times 2.3 \mathrm{~cm} .2009$ : T1

+ GAD coronal MRI (d), T1 +

GAD axial MRI (e) and axial flair MRI (f) measuring $2.0 \times 1.6 \mathrm{~cm}$. 2016: T1 + GAD coronal MRI (g), T1 + GAD axial MRI (h) and axial flair MRI (i) measuring $1.8 \times 1.6 \mathrm{~cm}$
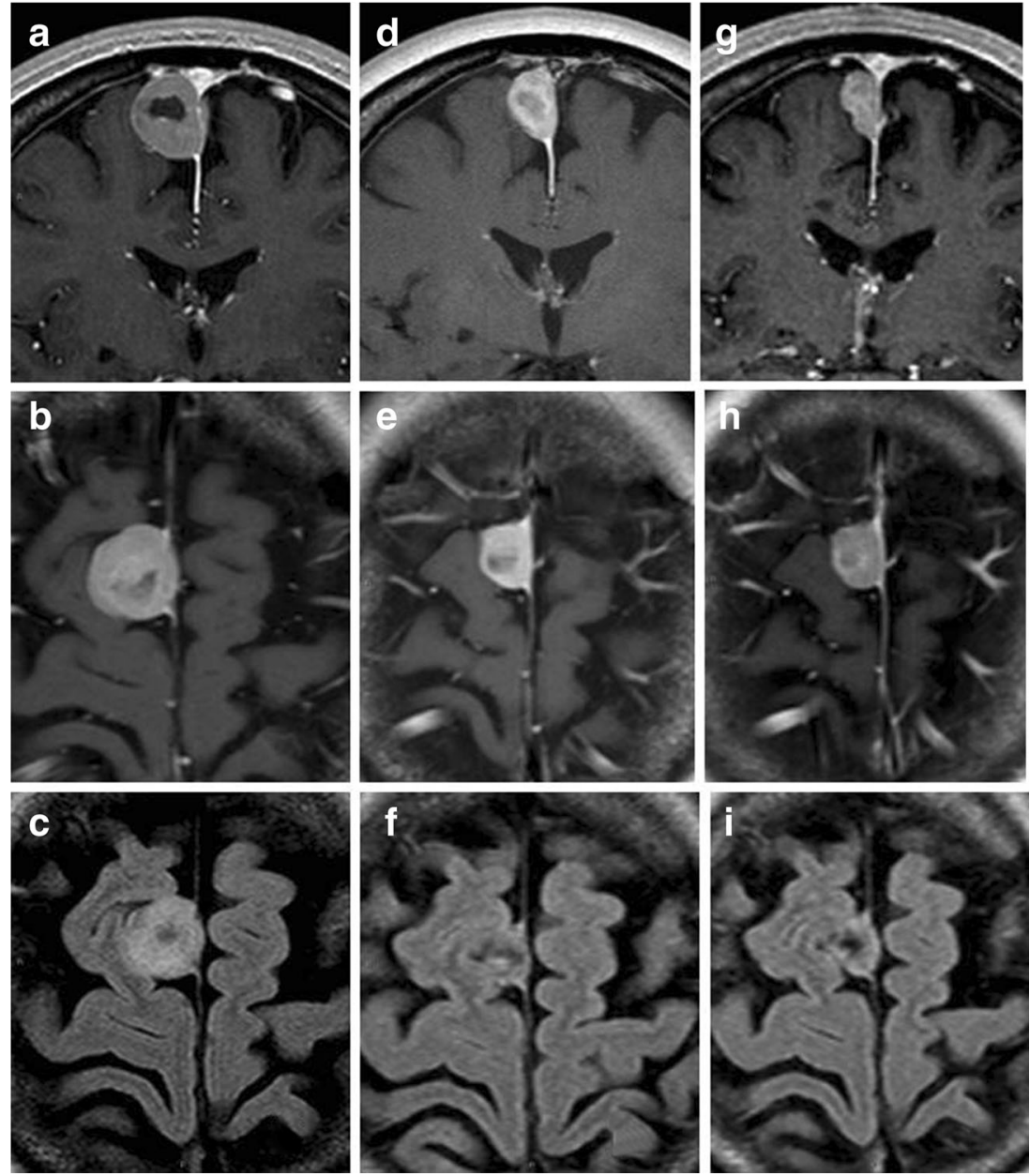